\title{
Smartphone addiction in students: A qualitative examination of the components model of addiction using face-to-face interviews
}

\author{
SAYMA JAMEEL $^{1 *}$, MOHAMMAD GHAZI SHAHNAWAZ ${ }^{2}$ and MARK D. GRIFFITHS ${ }^{3}$ \\ ${ }^{1}$ Faculty of Behavioral Sciences, SGT University, Gurugram, India \\ ${ }^{2}$ Department of Psychology, Jamia Millia Islamia, New Delhi, India \\ ${ }^{3}$ Psychology Department, Nottingham Trent University, Nottingham, UK
}

(Received: October 8, 2018; revised manuscript received: July 21, 2019; second revised manuscript received: September 10, 2019; accepted: September 22, 2019)

\begin{abstract}
Background and aims: Smartphone use has increased markedly over the past decade and recent research has demonstrated that a small minority of users experience problematic consequences, which in extreme cases have been contextualized as an addiction. To date, most research have been quantitative and survey-based. This study qualitatively examined the components model of addiction for both "addicted" and "non-addicted" users. Methods: A screening tool comprising 10 dichotomous items was administered to 40 college students. Of these, six addicted and six non-addicted participants were identified on the basis of their score on the screening tool and were asked to participate in a semi-structured interview. The interview questions were based on the components model of addiction comprising six domains (i.e., salience, withdrawal, conflict, relapse and reinstatement, tolerance, and mood modification). Directed content analysis was used to analyze the transcribed data and subthemes as well as emerging themes for the study as a whole were established. Results: There was some evidence of demarcation between smartphone addicts on the dimensions of salience, tolerance, withdrawal, and conflict. Mood modification was not much different in either group, and no participant reported relapse. Conclusions: The non-addicted group had much greater control over their smartphone usage than the addicted group on four (of six) aforementioned dimensions of behavioral addiction. Consequently, the main findings of this study provided good support for the components model of behavioral addiction.
\end{abstract}

Keywords: smartphone addiction, behavioral addiction, component model, directed content analysis, social factors, contextual factors

\section{INTRODUCTION}

One of the technological developments that has significantly changed human behavior and has become commonplace in modern society is the invention of the smartphone. A simple beep or flash from a smartphone has the potential to change an individual's mood and demands attention irrespective of the situation. Smartphones are Internet-enabled mobile phones and have multiple functions including storing information, accessing e-mails, taking photographs, listening to music, watching films/ videos, keeping schedules and reminders, writing notes, finding geographical locations, and installing programs, as well as telephone calling and texting. Consequently, such a small device has the potential to control many spheres of an individual's life. Because of this, the potential addictive nature of the smartphone cannot be ruled out and has been studied widely in recent years (e.g., Bianchi \& Phillips, 2005; Hooper \& Zhou, 2007; Hussain, Griffiths, \& Sheffield, 2017; Lapointe, Boudreau-Pinsoneault, \& Vaghefi, 2013; Tossell, Kortum, Shepard, Rahmati, \& Zhong, 2015).
At present, India (where this study was carried out) has 300-400 million smartphone users. There were 291.6 million smartphone users in India in 2017. It is extrapolated that the number of smartphone users will reach 490.9 million by 2022 (Tripathi, 2018). According to the Mobile Marketing Association (2016) in association with Kantar IMRB, the average consumer spends $3 \mathrm{hr}$ a day on their smartphones, which surpasses the time spent watching television and engaging in other media. Many young people report that they never turn off their smartphones, sleep with their smartphone next to them, and compulsively check their smartphones all through the day (Carbonell et al., 2012; Huffington, 2018). This has been termed as being "always on" and for many young people it has become the norm (Kuss \& Griffiths, 2017).

With the emergence of "always on" culture (Kuss \& Griffiths, 2017), there is a growing consensus among researchers concerning the existence of problematic smartphone

\footnotetext{
* Corresponding author: Asst. Prof. Sayma Jameel; Faculty of Behavioral Sciences, SGT University, Gurugram, Haryana 122505, India; Phone: +91 97182 16878; E-mail: saymajameel@ gmail.com
}

This is an open-access article distributed under the terms of the Creative Commons Attribution-NonCommercial 4.0 International License, which permits unrestricted use, distribution, and reproduction in any medium for non-commercial purposes, provided the original author and source are credited, a link to the CC License is provided, and changes - if any - are indicated. 
use (Salehan \& Negahban, 2013; Soror, Hammer, Steelman, Davis, \& Limayem, 2015). However, the conceptualization of smartphone addiction is still evolving (Panova \& Carbonell, 2018). Due to lack of consensus in conceptualization, the prevalence and incidence rates are typically overreported in the scientific literature (Billieux, Maurage, Lopez-Fernandez, Kuss, \& Griffiths, 2015). The issue is becoming further complicated because many terms are being used by different researchers to explore excessive/ problematic use of smartphones (Bian \& Leung, 2014; Lapointe et al., 2013; Tossell et al., 2015), mobile phone addiction (Bhutia \& Tariang, 2016), problematic mobile phone use (Beranuy, Oberst, Carbonell, \& Chamarro, 2009; Billieux, Van der Linden, \& Rochat, 2008; Merlo, Stone, \& Bibbey, 2013; Takao, Takahashi, \& Kitamura, 2009), mobile phone dependence (Chóliz, 2012; Lopez-Fernandez et al., 2017), compulsive mobile phone use (Hooper \& Zhou, 2007), and mobile phone overuse (Perry \& Lee, 2007; Soror et al., 2015).

The debate concerning which is the best terminology is beyond the scope of the present paper, even though Kuss and Griffiths (2017) noted that "these terms are used interchangeably by authors in the field" (p. 6). The present authors acknowledge that excessive use is not necessarily problematic and that some individuals may experience problematic behavior as a result of their smartphone without necessarily being addicted (depending upon the criteria used). The present authors are also aware that there is also a concern of pathologizing of an everyday behavior such as smartphone usage (Kardefelt-Winther et al., 2017). However, smartphone addiction research is an emerging area of research; therefore, more clearly defined criteria are needed as suggested by some of the authors in the field (e.g., Kardefelt-Winther et al., 2017). The present authors also take the view that individuals are no more addicted to smartphones than alcoholics are addicted to bottles and that smartphone addiction refers to the applications on the smartphone rather than to it (Kuss \& Griffiths, 2017). In this paper, "smartphone addiction" is used as an umbrella term (like "Internet addiction") to describe the totality of the problematic behavior on the smartphone rather than addiction to the physical device itself.

As it is very difficult to determine at what exact point smartphone use becomes an addiction (Griffiths, 2013), individuals (including researchers) may confuse habitual use of smartphone as an addictive behavior, and may end up pathologizing a common behavior, which should not be the case. Supporting the present authors' views, it has also been argued that excessive use does not necessarily mean addiction, and the difference between a healthy excessive enthusiasm and addiction is that healthy excessive enthusiasms add to life, whereas addictions take away from it (Griffiths, 2005). Researchers have further claimed that addiction is not an either-or-phenomenon where an individual is either an addict or not but needs to be viewed on a spectrum with different levels of severity, and that it is not always possible to define a specific threshold for such a subjective phenomenon. However, a non-addicted smartphone user can spend an identical amount of time on their smartphone as an addicted user, but the non-addicted smartphone user's time is more focused on concrete tasks and the use is largely functional causing few problems in the individual's lives (Tosell et al., 2015). As Griffiths (2010) has noted in relation to other problematic online behaviors, the content and context of technology use is far more important in determining addictive behavior than the time spent using the technology.

Most of the work on smartphone addiction is largely a-theoretical (Billieux et al., 2015; Kardefelt-Winther et al., 2017), and thus there is no consensus on methodology to be adopted to examine the construct of smartphone addiction. However, Griffiths (2005) proposed a components model of addiction, which suggests that all addictions comprise a core set of criteria and that a combination of the kinds of rewards (physiological and psychological) and environment (physical, social, and cultural) associated with any particular behavior will have a major effect on determining the likelihood of an excessive level of involvement in any particular activity. For Griffiths (2005), addiction is viewed as a biopsychosocial process and the components model helps to understand the processes. In this study, Griffiths' addiction framework was used to qualitatively examine smartphone addiction and was based on an extensive review of literature on addiction (Griffiths \& Larkin, 2004). There is evidence that this model can account for commonalities among all addictions and therefore smartphone addiction can also be examined from this framework. Griffiths (2005) lists six core components of addiction as being salience, mood modification, tolerance, withdrawal, conflict, and relapse. In relation to smartphone use:

- Salience - This occurs when smartphone use becomes the single most important activity in the person's life and dominates their thinking (preoccupations and cognitive distortions), feelings (cravings), and behavior (deterioration of socialized behavior).

- Mood modification - This refers to the subjective experiences that people report as a consequence of using their smartphone and can be seen as a coping strategy (i.e., they experience an arousing "buzz" or a "high" or paradoxically a tranquilizing feel of "escape" or "numbing").

- Tolerance - This is the process whereby increasing amounts of time spent on smartphones are required to achieve the former mood-modifying effects.

- Withdrawal symptoms - These are the unpleasant feeling states and/or physical effects (e.g., the shakes, moodiness, irritability, etc.) that occur when the person is unable to access their smartphone.

- Conflict - This refers to the conflicts between the person and those around them (interpersonal conflict), conflicts with other activities (social life, hobbies, and interests), or from within the individual themselves (intrapsychic conflict and/or subjective feelings of loss of control) that are concerned with spending too much time on their smartphone.

- Relapse - This is the tendency for repeated reversions to earlier patterns of excessive smartphone use to recur and for even the most extreme patterns typical of the height of excessive smartphone use to be quickly restored after periods of control. 
At present, there are many studies on smartphone addiction, almost all of which are cross-sectional and based on survey methodologies using convenience samples, which provide little depth as to how problematic smartphone use affects users at an individual level (e.g., Chen, 2006; Hooper \& Zhou, 2007; Igarashi, Motoyoshi, Takai, \& Yoshida, 2008; Koo, 2010; Leung, 2007, 2008; Martinotti et al., 2011; Perry \& Lee, 2007; Walsh, White, \& Young, 2010). However, there are a few qualitative studies and they used focus group interviews and/or semi-structured interviews with excessive smartphone users. Walsh, White, and Young (2008) conducted focus group discussions with 32 young people aged between 16 and 24 years to identify the psychological benefits arising from mobile phone use and whether mobile phone addiction was occurring among this group. Thematic analysis revealed that most youths were extremely attached to their phone exhibiting significant behavioral addiction symptoms as well as numerous benefits to users where the mobile phones were an intrinsic part of most young people's lives.

Lapointe et al. (2013) investigated addictive smartphone usage via 11 in-depth interviews with participants aged $17-29$ years. The data were analyzed using grounded theory and findings suggested that adopting traditional conceptualizations of addiction were not sufficient to define, understand, and manage smartphone addictive behaviors. Ko (2015) attempted to identify the problems of Christian students' excessive smartphone use in precipitating a psychological and spiritual conflict. Eleven in-depth interviews were conducted among individuals aged 19-26 years and data were analyzed using combination of the phenomenological and qualitative case-study methods. Five categories were derived via phenomenological qualitative analysis that included (a) addiction to smartphones, (b) isolation and alienation, (c) idolization of smartphone, (d) change and spiritual conflicts, and (e) keeping faith in digital world. Overall, the findings reflected that participants experienced both spiritual and psychological conflicts due to high volume of smartphone use.

Tossell et al. (2015) explored smartphone addiction focusing on how self-reported smartphone addiction related to monthly smartphone use. They employed a naturalistic and longitudinal telemetric approach. A total of 34 participants who did not own smartphone were given iPhones installed with program, which operated as a background process and monitored all usage over the course of a yearlong study. At the end of 1 year, users were asked to rate their level of addiction to the smartphone using the Smartphone Addiction Measurement Instrument and the Internet Addiction Test. Two thirds (62\%) claimed that they were addicted to their iPhones. The self-defined addicted users and non-addicted users' data were compared on the basis of recorded usage and it was found that self-defined-addicted users spent twice as much time on their smartphone and launched applications much more frequently as compared to non-addicted users.

It is evident from these studies that most of the studies were conducted on participants who claimed they were addicted to their smartphones (i.e., simply being asked whether they thought they were addicted to their smartphone). Although such studies increase our understanding about the experiences of smartphone "addicts" and provide a "window" to their inner world, they did not actually examine addictive symptoms and/or components in any great depth. To get a real "feel" of the inner world of smartphone addicts and to examine whether what is happening to them is unique to them, the inner world of the nonaddicts must also be examined alongside these accounts. For example, for smartphone addicts, their smartphone use would be the most salient thing in their lives as it would define them, and also provide a sense of who they are (Clayton, Leshner, \& Almond, 2015). This proposition is similar to Harkin's (2003) idea that the mobile technology becomes an intimate part of ourselves to the extent that they are capable of representing "an extension of our physical selves - an umbilical cord, anchoring the information society's digital infrastructure to our very bodies" (p. 16). Such a conceptualization may or may not be found among non-smartphone addicts. Consequently, this study involves such a comparison. To the best of the present authors' knowledge, no previous qualitative study has ever been carried out examining individual experiences of smartphone use in this way. The qualitative study by Walsh et al. (2008, p. 88) recommended that "future research could attempt to identify the specific symptoms that differentiate addicts and non-addicts mobile phone users."

This study attempts to fill evident gaps in the smartphone addiction literature. First, much of the previous research into smartphone addiction has arguably been a-theoretical. The study utilized Griffiths' (2005) components model of behavioral addiction to frame the interview questions (both at initial screening level and for the main study) and thus aimed at testing the validity of this model. Second, the study interviewed both smartphone addicts and non-smartphone addicts. This was conducted to establish the extent to which the six addiction components are indeed the unique features of smartphone addicts as compared to non-smartphone addicts, thus providing more support to the behavioral addiction model.

\section{METHODS}

\section{Participants and procedure}

This study was conducted in two stages. In Stage 1, screening was carried out to identify addicted and nonaddicted users. Forty participants aged 18-23 years volunteered for the study in this phase. The participants were all undergraduate students from a private university in the National Capital Region of Delhi (India). In a classroom setting, the participants were asked to complete sociodemographic questions and Griffiths' (2013) screening questions that contained 10 dichotomous items, which were used to select addicted and non-addicted smartphone users. Exemplar questions included: "My mobile phone is the most important thing in my life," "I use my mobile phone as a way of changing my mood," and "I have lied to other people about how much I use my mobile phone." Participants who scored 5 or less (out of 10) were classed as "non-addicts" and those who scored of 6 or more (out of 10) were classed an "addicts." 
Following this, six participants were randomly selected from each of the two groups to participate in the second stage of the research. In Stage 2, these 12 interviewees were interviewed at length using a semi-structured interview format. Interviews were digitally recorded and all participants provided informed consent to take part in the study. All audio recordings were transcribed verbatim. One-to-one interviews were conducted with each participant. The duration of each interview was between 20 and $45 \mathrm{~min}$ with the average interview lasting $30 \mathrm{~min}$. The number of words in the transcribed interviews ranged from 1,184 to 1,820 . The average time spent by participants classed as "addicted" to their smartphone was $9.1 \mathrm{hr}$ a day compared to $2.9 \mathrm{hr}$ in the non-addict group, which provided some face validity for the two groups (Table 1).

A qualitative content analytic method was chosen as a method to "provide knowledge and understanding of the phenomenon under study" (Downe-Wambolt, 1992, p. 314). Hsieh and Shannon (2005) defined qualitative content analysis as a research method for the subjective interpretation of the content of text data through the systematic classification process of coding and identifying themes or patterns. As the purpose of the present paper was to test Griffiths' (2005) components model of behavioral addiction, a directed content analysis method was used because "the purpose of this method is to validate or extend a theoretical framework or theory" (Hsieh \& Shannon, 2005, p. 1281). In this study, existing theory is used to develop research questions leading to the development of questions for the semi-structured interview. However, too much dependence on theory might blind the researchers to ignore the contextual aspects of the phenomena. To overcome this bias, the first two authors independently examined the themes and subthemes as they emerged in the process of analysis and evaluated whether they fitted well with the component model of behavioral addiction or not. The themes and subthemes were then examined and confirmed by the third author.

\section{Semi-structured interview schedule}

The semi-structured interview schedule was developed using the components model of addiction (Griffiths, 2005).
The participants were asked about their experiences with smartphones. Questions and the prompts are listed below: (a) "What does your mobile phone mean to you?" [salience]. This was often followed by prompt such as "How do you feel about your smartphone? How important it is for you? What place does it have in your life? Has smartphone made your life better? So how has it made your life better? How does mobile phone affected your sense of self? (b) Have you ever used phone to change your mood? [mood modification]. This was followed by prompt such as "Does anything making it better or worse? (c) "Have you noticed any change in your use of mobile phone over time?" [tolerance]. (d) "Tell me about your experience of being away from your phone or when you were unable to use your phone?" [withdrawal]. This was followed by prompts such as "What happened? How did you feel at that time?" (e) "How is your life and work getting affected by mobile phone? [conflict]. (f) "Tell me about your experience when you tried to reduce your use of mobile phone" [relapse]. This was followed by prompt such as "How do you feel at that time?"

\section{Data analysis and interpretation}

The directed content analysis method follows the deductive use of theory (Hickey \& Kipping, 1996; Potter \& LevineDonnerstein, 1999) to analyze the text data. First, all transcripts were coded into broad categories on the basis of predetermine category of component model of addiction. After coding, the data were examined for each category to determine whether subcategories were needed for that category. Common concepts, which emerged in the focusing questions across the interviews, were identified as themes. An iterative process was used in which transcripts were coded and recoded until no new themes or addiction symptoms emerged. In addition, commonalities and differences among participants' views were noted. Data that could not be coded into one of the six components derived from the components model were reexamined to describe different manifestations, which were then subsumed under one of the six components if found related to some extent. In the final stage, the subthemes and themes for the study as a whole were established.

Table 1. Participants' demographic characteristics and Smartphone Addiction Test scores

\begin{tabular}{|c|c|c|c|c|c|c|}
\hline Participant & Age (years) & Sex & Place of current residence & $\begin{array}{l}\text { Average hours spent on } \\
\text { smartphone (in } \mathrm{hr} \text { ) in a day }\end{array}$ & Test score & $\begin{array}{c}\text { Addicted/ } \\
\text { non-addicted }\end{array}$ \\
\hline 1 & 19 & $\mathrm{M}$ & Students' residence & 3 & 1 & Non-addicted \\
\hline 2 & 20 & M & With parents & 1 & 0 & Non-addicted \\
\hline 3 & 19 & $\mathrm{~F}$ & Students' residence & 2 & 2 & Non-addicted \\
\hline 4 & 19 & $\mathrm{~F}$ & With parents & 5 & 4 & Non-addicted \\
\hline 5 & 20 & $\mathrm{~F}$ & Students' residence & 1.5 & 4 & Non-addicted \\
\hline 6 & 21 & M & With parents & 5 & 0 & Non-addicted \\
\hline 7 & 18 & $\mathrm{~F}$ & With relative & $8-10$ & 6 & Addicted \\
\hline 8 & 19 & $\mathrm{~F}$ & With parents & 15 & 6 & Addicted \\
\hline 9 & 19 & $\mathrm{~F}$ & Students' residence & 12 & 8 & Addicted \\
\hline 10 & 20 & $\mathrm{~F}$ & Students' residence & 12 & 8 & Addicted \\
\hline 11 & 20 & $\mathrm{~F}$ & With parents & $1-2$ & 6 & Addicted \\
\hline 12 & 19 & $\mathrm{~F}$ & With parents & 4 & 6 & Addicted \\
\hline
\end{tabular}


Ethics

The study was approved by the Institutional Ethics Committee of Jamia Millia Islamia (Social Sciences), New Delhi, India. The study procedures were carried out in accordance with the Declaration of Helsinki. All participants were informed about the study and provided informed consent prior to participation. Participants were told that there was no inherent risk involved in this research. They were also informed that their participation in research was voluntary and they could leave without giving any reason. They were also assured of anonymity and confidentiality and that their identity would not be disclosed to anyone outside the research team.

\section{RESULTS AND PRELIMINARY DISCUSSION}

\section{Key theme 1 - Salience}

This refers to how important and prevalent smartphones were in the lives of individuals. Salience and its subthemes were manifested differently and to varying degrees in the two groups (see Table 2 and Supplementary Material for detail). Major themes and subthemes with selected excerpts are presented below:

Positive valence. All the six addicted participants reported that their smartphone had made life better in some way. Four participants said that phone should be with them all the time even when they were not using it. Four of the participants also reported that smartphone was important for them and meant a lot to them. For one of the participants, it had some importance and reported she would not have withdrawal symptoms when it was not beside her and was not more important than her family. Thus, for most of the smartphone addicted group, the smartphone was very salient and the need of proximity to their smartphone was apparent. The participants described that even if there was no urgency, there was always been "clinginess" associated with the smartphone as exemplified by the following:

Never felt like keeping [my smartphone] away from me. As such I have never left the phone. I use for it for around

Table 2. Summary of key theme of "Salience" and subthemes

\begin{tabular}{|c|c|c|}
\hline $\begin{array}{l}\text { Key theme 1: } \\
\text { Salience }\end{array}$ & Addicted group & Non-addicted group \\
\hline Theme & Positive valence & $\begin{array}{l}\text { Limited positive } \\
\text { valence }\end{array}$ \\
\hline Subthemes & Need of proximity & $\begin{array}{l}\text { Distance does not } \\
\text { bother } \\
\text { Controlled usage }\end{array}$ \\
\hline Theme & Sense of self & Sense of self \\
\hline \multirow[t]{3}{*}{ Subthemes } & $\begin{array}{l}\text { Attachment/ } \\
\text { extended self }\end{array}$ & $\begin{array}{l}\text { Negativity about } \\
\text { oneself }\end{array}$ \\
\hline & More busyness & $\begin{array}{l}\text { Intrusion in personal } \\
\text { space }\end{array}$ \\
\hline & $\begin{array}{l}\text { Extinction of } \\
\text { hobbies }\end{array}$ & \\
\hline
\end{tabular}

eight hours... I have two phones... I may use it or not use it. I want to have a charged phone with me always, either I touch it or I do not. It should be near me always... It is not more important than my family members ... My family is more important ... [my smarpthone is] just a gadget for me. (Participant 7; addicted)

Actually things are different when I am at home...I do not have to look at mobile phone a lot ... I usually spend time with my siblings... here things are different ... I am alone so all I get to do is mobile phone... so in [the] college hostel [a] mobile phone is very much required. (Participant 10; addicted)

I feel it should be there. Like, even if I am not using it, I still want it with me. Even if it is switched off I am not using or I am doing some other work either in kitchen or any household chores ... anything ... I want it to be with me. (Participant 12; addicted)

Some participants even expressed the anxiety and/or uneasiness about receiving and responding immediately to text messages. They also recalled concurrent use with other activities but taking up a significant part of their activity.

If somebody sent even just 'hello', I feel like replying straight away... Don't want to delay it. Sometimes I feel like replying after two hours or so... like let the notification come... but sometimes it is not possible to hold myself from replying just then. (Participant 12; addicted)

For non-addicted smartphone participants, all six participants reported that life was better with smartphone apart from one who felt irritated after overusing it. Only one participant in the non-addicted group said the smartphone was important to them. Two said it was not important at all, two participants said it was important to some extent, and one felt that they should learn to maintain balance. Therefore, for non-addicted participants, the smartphone was not salient despite it being a useful device. For example:

I really don't like carrying a phone at all because I feel very irritated when I use phone a lot... I don't find any meaning of using phone for a lot of the time ... except for communication. (Participant 2; non-addicted)

Phone is necessary for me till one point...going outside... When I am going far from my place... and even at home it is necessary till a limited time... It is not that important ... that I have to be with phone all the time... If I'm outside I might need to call my mom and dad or they might call me, or if I have gone out for some work then I might need to call my teacher to inform or some faculty to inform or my friend to inform, that time phone is needed... When phone is required then only I take care of it ... otherwise even if the phone is kept it won't matter to me that much. (Participant 4; non-addicted)

If I am going for dinner and I don't think it is needed there, then I can leave it. (Participant 4)

Attachment/extended self/change in self. Two of the smartphone-addicted participants reported high attachment 
with their smartphones as compared to none from the non-addicted smartphone participants. One of the addicted participants felt that their smartphone was an extension to their self. For example:

[The phone] is a second hand or a third hand maybe... Without my mobile phone, life is not possible...Yes, it does mean a lot to me. I do take care of it ... Each and every memory, my data, my everything is recorded in it. So I do have some attachment with it. (Participant 8; addicted)

My mobile phone is like a friend... If I get bored, I use Instagram...Facebook... or I can call a friend, it satisfies many needs of mine ... in a way as I'm attached to some of my friends...I am attached to my smartphone. (Participant 9; addicted)

For some of the participants, their smartphones also brought about some changes in their attitude and behavior leading to change in their self. Three of the smartphone-addicted participants said that their smartphone had negatively affected their sense of self (because they had become lazier, at times lost, and not in the proper state of mind), one participant felt that it had affected her in both positive and negative ways, while two of the non-addicted participants were not sure about this. However, all six non-addicted participants reported that smartphone had not impacted their sense of self, even though two participants felt negative about themselves when they overused their smartphones.

Sometimes because of this mobile phone, somehow I feel lost. When people are talking ... and like you are busy on your mobile phone... Especially with friends... Like you are not in a proper state sometimes. (Participant 10 ; addicted)

Most of the time rather than interacting with people, one keeps himself busy on the phone. (Participant 11; addicted)

When my phone was not there, I used to write articles ... I was very creative... now I feel ... who will do this hard work instead? I just find stuff on Google . . earlier I used to do all assignments on my own...now I have become lazy...the data is easily available...I used to have hobbies... now I don't think I have any. (Participant 9; addicted)

However, in the non-addicted group, the change in self was different. For example:

I feel negativity about myself about why I am doing this ... I should not do that I should be more focused on my study or books. (Participant 4; non-addicted)

I feel very irritated when I use the phone a lot ... I don't find any meaning of using phone for a lot of time. (Participant 2; non-addicted)

The above descriptions highlight that smartphone use had made life easier for both groups of participants because it had many uses and applications. Despite this commonality, there was a difference between addicted and non-addicted participants in terms of the salience of smartphones in their lives. The results of this study concur with the study by Bodford, Kwan, and Sobota (2017), which showed reliance on - or "clinginess" toward - smartphones, compulsive urge to answer one's phone, and where smartphone addiction was framed in terms of possession attachment. The attachment and proximity-seeking theme aligns with Han, Kim, and Kim (2017), who found that users perceive smartphones as their extended selves. Such users were more likely to get attached to their smartphones, which, in turn, led to nomophobia by heightening the phone proximity-seeking tendency.

As mentioned above, some users see smartphones as the expression of their self or even the extension of their self (Belk, 1988, 2013). Many young smartphone users personalize their smartphone with unique ringtones and screensavers as an expression of their identity and consider their smartphone as the symbol of their self-identity (Katz \& Sugiyama, 2005). Personal memories evoked by smartphones encourage users to extend their identity onto their smartphones (Han et al., 2017). The participants in this study also used smartphones as a diary for writing their innermost thoughts and felt assured about their safety and privacy. While smartphones remained one of the most (if not the most) important aspects of the self of those in the "addicted" group showed clinginess/attachment leading to impulsive use whereas in the non-addicted group, the use of the smartphone was more controlled.

\section{Key theme 2 - Mood modification}

This theme refers to the subjective experience that people report as a consequence of engaging with their smartphone. Subthemes and selected excerpts are presented in Table 3.

Relaxing/destressing agent. All the participants of both groups used smartphone to modify their moods by engaging in downloading applications, listening to music, watching movies/videos, writing notes in the diary, calling family and friends, etc. They did it to escape or distract themselves from the problems or distress and for entertainment, as well as a way to alleviate boredom. However, both the groups differed as to what happens after the initial temptation to

Table 3. Summary of key theme "Mood modification" and subthemes

\begin{tabular}{lcc}
\hline $\begin{array}{l}\text { Key theme 2: Mood } \\
\text { modification }\end{array}$ & Addicted group & $\begin{array}{c}\text { Non-addicted } \\
\text { group }\end{array}$ \\
\hline Theme & Relaxing/destressing & $\begin{array}{c}\text { Relaxing/ } \\
\text { destressing }\end{array}$ \\
Subthemes & $\begin{array}{c}\text { Personal sense with } \\
\text { smartphone } \\
\text { Escaping from } \\
\text { problem } \\
\text { Entertainment }\end{array}$ & $\begin{array}{c}\text { Escaping from } \\
\text { problem } \\
\end{array}$ \\
& $\begin{array}{c}\text { Removal of } \\
\text { boredom } \\
\end{array}$ & $\begin{array}{c}\text { Burdensome when } \\
\text { overuse }\end{array}$ \\
\hline
\end{tabular}


use smartphone to alleviate mood. For all the smartphone addicts, the mood change was temporary. Two participants reported it helped in diverting the focus from problems temporarily, and two participants reported it did not help in the long run because the smartphone itself became the source of problems. One participant said the mood-changing qualities of smartphone use depended upon the initial mood and tension they felt. All the six non-addicted smartphone participants felt that smartphone lifted their mood. However, they all said that if they used it more, then there was a negative experience such as being irritated, losing enthusiasm, feeling tired, neglecting studies, etc.

When I feel like crying. I write notes in the phone, I get relief from it. I write notes when something is wrong internally with me. My family don't like it when I write a personal diary so I use the phone... nobody gets to know then. (Participant 7; addicted)

If I am sad I use my mobile phone as I can watch movies... Or call to a friend or someone or I will just scroll to the social site and I try to feel better. It actually works, distracting my mind from the main cause. (Participant 8; addicted)

I play funny videos... Or look at the pictures like... Good memorable ones... Usually I used to watch my favourite episode of wrestling... So it's makes me like I forget the situation that has happened. (Participant 10 ; addicted)

I want to watch songs and stuff to entertain myself when I am bored. (Participant 3; non-addicted)

When I use it more... Watch too many videos...too much mobile phone use... I lose enthusiasm in life...I become lazy to do other stuff. It takes away my activeness to do other activities. (Participant 2; non-addicted)

Sometimes I feel bad as I am ignoring my books and use mobile phone to entertain only. (Participant 3; nonaddicted)

The mood-modification component of smartphone use has been examined in previous research. For instance, Bian and Leung (2014) asserted that the use of smartphone can be seen as a way of escape from problems or to relieve a dysphoric mood (e.g., feeling of isolation, anxiety, loneliness, and depression). Griffiths (2015) reported that adolescents might engage in problematic technology use to feel part of their peer group, to modify their mood state, and/or to escape other problems in their lives. Research has also shown that problematic technology use can be present with other underlying comorbid problems such as depression, dysfunctional family life, physical disability, and lack of direction or purpose of life (e.g., De-Sola Gutiérrez, Rodríguez de Fonseca, \& Rubio, 2016; Király, Nagygyörgy, Griffiths, \& Demetrovics, 2014). Consequently, their smartphone usage might be associated with an escaping or avoidant coping style. Addictive use of smartphones can also be related to experiential avoidance and associated with the intrapsychic and emotional aspects of such behavior (García-Oliva \& Piqueras, 2016).
The difference between the addicted and non-addicted groups was not so distinct in relation to mood modification because both groups used smartphones to escape from problems and stress, or for entertainment and/or relieving boredom. Participants in the non-addicted group expressed irritation, being tired, neglecting studies following occasional excessive use of smartphones reflecting negative reinforcement. The mood modification was not long term or permanent even for addictive users.

\section{Key theme 3 - Tolerance}

It refers to how much increasing amount of time spent on smartphones is required to achieve the former mood-modifying effects. Subthemes and selected excerpts are presented in Table 4.

Contextualized use. For both groups, some contextual factors led to increased usage (e.g., having more free time, being away from home, being attached to someone, being on a holiday, having a new phone, etc.). All the 12 participants from both the groups shared this experience. However, four of the six non-addicted participants emphatically said that whenever they realized they used their smartphone more, they could reduce or control the usage. However, none of the addicted participants said so.

In holidays, I use it more and more... when I am at home during holidays...there is nothing much to do...not much outdoor activities...you can either talk to people at home or you can use phone. (Participant 7; addicted)

When there is nothing to do I am getting bored so I just scroll net sites, social sites and all... It depends it is not that is it has increased or it has decreased... It depends on days and the mood. That's it...not the permanent increase. (Participant 8; addicted)

I realize in a day that today I used it more . . . then I don't let it become more .. . like if holidays are there then it will increase. (Participant 2; non-addicted)

Yes it is increasing...But not excessively...It is like... actually I divide the time... Like these days we don't have much study to do... So I spend most of the time on mobile... But in exam time you know you need to work... So you can control it there. (Participant 5; non-addicted)

Table 4. Summary of key theme "Tolerance" and subthemes

\begin{tabular}{lll}
\hline $\begin{array}{l}\text { Key theme 3: } \\
\text { Tolerance }\end{array}$ & Addicted group & Non-addicted group \\
\hline Theme & Contextual usage & Contextual usage \\
Subthemes & Availability of & Availability of free \\
& free time & time \\
& Attachment with & Proper division of time \\
& friends & for use \\
& Away from home & Realization/insight \\
& & Negative effect \\
& & Command over use \\
\hline
\end{tabular}


I have a good command over using my mobile phone... Yes I have experienced that when I play games on my mobile phone... I feel very stressed when I play for 3-4 hours continuously in a day. So I usually take one or two hours in a day to play games on mobile phone... When I use in excess Ifeel stressed. (Participant 6 ; non-addicted)

However, when examining tolerance in the context of smartphone addiction in many cases, it was specific context or a situation that led to increased usage. Half of the participants in this study were living in university residences, away from home and family, and some of them were also in relationship (not asked specifically but this arose during the interviews). Most of the academic and cocurricular notices were sent via WhatsApp groups, and vacations after examinations were among the situational factors that may have enhanced smartphone usage. In modern society, the virtual world has become the "real world" for many users, and interaction/ communication via social media is preferred over the traditional medium to many online users (Kuss \& Griffiths, 2017). James and Drennan (2005) suggested that situational factors associated with addictive smartphone consumption may lead to negative consequences. However, there was a difference in the usage because most of the non-addicted smartphone participants had control over usage and they were mindful of how to use their smartphone.

\section{Key theme 4 - Withdrawal}

Withdrawal refers to unpleasant feeling states and/or physical effects (e.g., the shakes, moodiness, irritability, etc.) that occur when the person is unable to access their smartphone because of any reason. Subthemes and relevant excerpts are presented in Table 5.

Anxiety/uneasiness and strange feeling. Five addicted participants experienced anxiety, frustration, and/or irritation when unable to use their smartphone, and four reported a fear of missing out (FOMO) when there were unable to use smartphone because of dead batteries or network failure issues. Two of non-addicted participants longed for it when they were unable to use it and also experienced strange feelings. One of the non-addicted participants reported that they might miss out something. Three non-addicted participants said that it felt okay if they were unable to use their smartphone, whereas one of these participants shared said it was a struggle to do so.

I become slightly tense if the phone is not charged properly... what if I get some call ... although I don't

Table 5. Summary of key theme "Withdrawal" and subthemes

\begin{tabular}{|c|c|c|}
\hline $\begin{array}{l}\text { Key theme } 4 \text { : } \\
\text { Withdrawal }\end{array}$ & Addicted group & $\begin{array}{l}\text { Non-addicted } \\
\text { group }\end{array}$ \\
\hline Them & Anxiety/uneasiness & Strange feeling \\
\hline \multirow[t]{2}{*}{ Subthemes } & $\begin{array}{l}\text { Fear of missing out } \\
\text { (FOMO) }\end{array}$ & $\begin{array}{l}\text { Fear of missing out } \\
\text { (FOMO) }\end{array}$ \\
\hline & Longingness & $\begin{array}{l}\text { No noticeable } \\
\text { distress }\end{array}$ \\
\hline
\end{tabular}

get call except my mother... phone should be with me all the time... I may touch it or not touch it ... I have never stayed away from my phone...there is just fear that something will be missed. (Participant 7; addicted)

Recently, I went to a village and there was no network available... I was unable to use my phone... I was very uncomfortable in the beginning (2-3 days) as I have this habit of using it for everything and daily... I was really anxious, got bored, I tried disparately to connect with the Internet, but without luck...It was really bad. (Participant 9; addicted)

For the past 20 days, I did not use phone mostly and I reduced it to an hour or an hour and 30 minutes ... I can see notifications... I feel anxious as I am fond of [the] phone...I try to keep busy in other stuff such as looking after mom and dad or family trip... but I am missing phone [and what is] happening...however, when I go out, I don't feel that bad. (Participant 9; addicted)

I have been cutting down...I use it only after studies after $10 \mathrm{pm}$ for one hour and morning to check the group ... I am trying to cut it down a bit... it's just fine but sometime there is this longingness... I have been used to it before sometime... I feel like just checking. (Participant 1; non-addicted)

Strange... when you use your mobile phone all the time and when there are times that you cannot use it ...yeah you feel kind of strange... may be I am missing out something...yeah there is a bit of different feeling. (Participant 2; non-addicted)

If I have no work...then I will have no problem in staying away from phone. (Participant 5; nonaddicted)

One of the interesting aspects of withdrawal was the presence of FOMO in both the groups but differed in intensity. The presence of FOMO and the feeling of longingness in some of the non-addicted participants were slightly unexpected. This indicates the constant urge of young group of users to stay updated and be "ever present in" their social world, where individuals cannot afford to miss out on anything (Kuss \& Griffiths, 2017). Smartphone apps make it easier to share and to check friends' status updates, and they offer individuals a chance to stay in touch 24/7 without regard to the place and time, thus increasing the opportunity and frequency of engaging with social media platforms (Salehan \& Negahban, 2013) and seeking out social information constantly. The differentiating factor between addicted and non-addicted participants was the absence of distress among non-addicted participants as compared to addicted participants on withdrawal component.

\section{Key theme 5 - Conflict}

Conflicts can be intrapersonal or interpersonal and these are arising because of spending too much time on their smartphone. Subthemes and relevant excerpts are presented in Table 6 . 
Table 6. Summary of key theme "Conflict" and subthemes

\begin{tabular}{|c|c|c|}
\hline $\begin{array}{l}\text { Key theme 5: } \\
\text { Conflict }\end{array}$ & Addicted group & $\begin{array}{l}\text { Non-addicted } \\
\text { group }\end{array}$ \\
\hline Theme & With family/friends/work & $\begin{array}{l}\text { With family/ } \\
\text { friends/work }\end{array}$ \\
\hline \multirow[t]{2}{*}{ Subthemes } & $\begin{array}{l}\text { Distraction in studies } \\
\text { Difficulties in maintaining } \\
\text { relationships with } \\
\text { family/friends }\end{array}$ & $\begin{array}{l}\text { Intrusion in } \\
\text { personal space }\end{array}$ \\
\hline & Strengthen relationship & $\begin{array}{l}\text { Distraction in } \\
\text { studies }\end{array}$ \\
\hline
\end{tabular}

With family/friends and life/work. Almost all the participants (six from addicted group and four from non-addicted group) felt that smartphone led to conflicts because smartphone had impacted their academic studies and relationships with family and friends. Two participants in each group reported that they received negative comments or taunts from their family and friends when using smartphones excessively and created problems for them. However, smartphone-addicted participants did not try to justify this, whereas non-addicted participants justified their use to parents as being for studies and other positive usage. One smartphone addict viewed it as a medium that ensured safety of their loved ones and strengthened their relationship with them despite having conflict. Two non-addicted participants reflected that smartphone use had caused an unnecessary intrusion into their personal space. One non-addicted participant felt that their smartphone use had more positive than negative outcomes. Two non-addicted participants also felt it was all about controlled usage.

The phone does affect our life... like during exam time we require phones as much of the stuff is in the phone itself . . but if a message occurs or a notification occurs or social networking sites... we get affected and distracted from (studies) ... even during class time...we get distracted and interrupted because of these... it's really disturbing. (Participant 8 ; addicted)

[The phone] affects my life. Earlier when I didn't have phone, I used to study more... really more...I had second rank in my class...now I am an average student ... phone really distracted me ... now I find study boring... when I use during exam time... I could not have control and the use get extended...My mom always complained that I am on phone all the time... it created huge problem between us. (Participant 9; addicted)

My mobile phone has provided strength to the relationship ... for me it works in a good way more rather than a wrong way... I am in touch with my family all the time that makes it good ... sometime it has resulted in conflict also...because through mobile phone we cannot express our feelings like we do in person... conflict is also happening because of social media and FB and all that...so it has both roles. (Participant 10; addicted)
We are so used to mobile phone/social networking and If someone is not talking or not replying then we have fights... and it creates lot of distance between us and we are not talking to each other for even longer time... that further creates problem in the relationship. (Participant 11 ; addicted)

Mobile phones have disturbed our time management...so in this way it has affected relationships ... many times we are unable to make our parents understand that everything is on the phone... it has better usage too... I use it for my betterment, to gain knowledge, so this causes conflict. (Participant 5; non-addicted)

Positive ... as mobile phone can do things in few minutes ... but in negative way... like someone wants to talk to you and you are doing work and again and again messaging you... and you are doing work for few minutes and talk to them ... so in negative way... it may disturb you... it's not so often ... it has not affected my life in negative way. (Participant 6; non-addicted)

Smartphones had negatively impacted most of the participants of both the groups in major domains of life. According to a Pew Research Centre (Smith, Rainie, McGeeney, Keeter, \& Duggan, 2015) report, $73 \%$ of 18 - to 29 -year-old smartphone owners felt "distracted" during study periods. There is also evidence that smartphone usage has negative implications for health, relationship, and work (Kuss \& Griffiths, 2017). For one of the smartphone addicts, smartphone use had also contributed in strengthening their relationships with family and friends. Cassidy (2006) reported that many youths associated mobile phone use with number of positive attributes, such as enhancing their membership within a group, positive peer approval, and maintaining social connections. Some of the non-addicted smartphone users felt that it has intruded into their personal lives and they tried to explain to parents that it is a useful device and being used in a productive manner, sometimes successfully and sometimes not so. They also tended to explain to friends why they had not replied to them immediately, which created relationship maintenance anxiety (Ehrenberg, Juckes, White, \& Walsh, 2008).

\section{Key theme 6 - Relapse}

This theme refers to the tendency for repeated reversions to earlier patterns of the particular activity to recur after following abstinence and control from smartphone use. Two smartphone addicts never tried to reduce their smartphone use because they always carried smartphone irrespective of whether they are using it or not. However, they said that they would experience anxiety if they have to reduce their usage. Four smartphone addicts had reduced their usage gradually and had experienced anxiety. They also said they were missing out what was happening on social media. However, they managed to control themselves by going out, reading novels, and following Buddhism practices. For one of these participants, Buddhist prayers helped her to control the anxiety of not using her smartphone. On the other hand, all six non-addicts attempted to reduce the use of 
smartphone by adopting different strategies such as charging the phone in one corner of the room, following a strict schedule, following a healthy life style, etc. Two nonaddicts had full control over their smartphone usage and said if work was important then the smartphone can be switched off without any problem (Table 7).

Self-management. Ten of the participants (including all six non-addicts) had at some point reduced their use of smartphones with some success by adopting various selfmanagement techniques.

The thought never came that we have to reduce its use as I have had never any problem with it ... As such I never remained away from the phone...I have never left my phone anywhere... In fact I have two phones... never feel like keeping it away from me. (Participant 7; addicted)

Many times I tried to stop use of my phone... I tried to engage myself in other activities like outdoor games, reading books, and reading novels to divert my mind and not pay attention to phone... if the other task is interesting ...then its ok. (Participant 11; addicted)

I tried to reduce my usage of smartphone... in the beginning I reduced it to half an hour, then an hour, then one and half hour and gradually it reduced. (Participant 12; addicted)

I am working on it ... but I have addiction to phone... like I feel checking again and again and coming online very often... I keep myself busy in activities such as drawing and do not pay much attention to phone...I also follow Buddhism...do morning and evening prayer... all these help and reduces anxiety/pressure of not using phone for long ... there is some control . . as I used to check the phone as soon as I used to get up ...checking it always ...now I can check after one or two hours. (Participant 12; addicted)

I am trying to cut it down a bit, sometimes I feel like just checking ... I kept it on charging it somewhere ... and it remains just on the study table... I did it quite successfully. (Participant 1; non-addicted)

Yes, I am able to reduce... Sometimes I have a specific work which needs to be completed... so I have a very good control on myself... I feel very happy that today I didn't use the phone and my work also got completed ... this makes me very happy... It's all about control, self- control and how we manage it. (Participant 5; non-addicted)

Table 7. Summary of key theme "Relapse" and subthemes

\begin{tabular}{|c|c|c|}
\hline $\begin{array}{l}\text { Key theme 6: } \\
\text { Relapse }\end{array}$ & Addicted group & Non-addicted group \\
\hline \multirow{3}{*}{$\begin{array}{l}\text { Theme } \\
\text { Subthemes }\end{array}$} & Self-management & Self-management \\
\hline & $\begin{array}{l}\text { Inconsistent pattern } \\
\text { of use }\end{array}$ & Successful attempt \\
\hline & $\begin{array}{l}\text { Slow gaining of self- } \\
\text { control }\end{array}$ & $\begin{array}{l}\text { Better command } \\
\text { over usage }\end{array}$ \\
\hline
\end{tabular}

There are studies which show that addictive patterns of smartphone use are associated with specific impulsivity traits, such as urgency (i.e., the tendency to act rashly in emotional contexts), lack of planning/premeditation (i.e., the tendency not to take into account the consequences of actions), and/or low self-control (i.e., defined as a tendency to act in an automatic rather than in a controlled way; Billieux et al., 2008; Khang, Kim, \& Kim, 2013).

\section{GENERAL DISCUSSION}

This study used components model of behavioral addiction (Griffiths, 2005) to examine the experiences of addicted and non-addicted smartphone users. At a time when being "online" is a cultural norm (Kuss \& Griffiths, 2017) and smartphone use/abuse reflects behavior that can be considered congruent with certain life styles (Toda, Monden, Kubo, \& Morimoto, 2006), the distinction in behaviors between addicted and non-addicted smartphone users is helpful in theory development and clinical practice for smartphone addiction in particular and behavioral addiction more generally.

This study provides a novel contribution to the existing literature because previous research on smartphone addiction has been accused of suffering from conceptual and methodological problems, particularly when using survey designs (Kuss \& Griffiths, 2017). However, the components model of behavioral addiction has been found to be relevant in explaining many behavioral addiction including addictions to exercise (Griffiths, Szabo, \& Terry, 2005), gaming (Lemmens, Valkenburg, \& Peter, 2009), work (Andreassen, Griffiths, Hetland, \& Pallesen, 2012), social media use (Andreassen et al., 2016), mobile phone use (Billieux et al., 2015), sex (Andreassen, Pallesen, Griffiths, Torsheim, \& Sinha, 2018), and Internet use (Kuss, Shorter, Van Rooij, Griffiths, \& Schoenmakers, 2013). All of these studies have used empirical methods to assess behavioral addiction, and this is the first study to test the validity of behavioral addiction for smartphone users by comparing in-depth accounts of both addicted and non-addicted smartphone users.

In this study, the component of salience was found to be high among addicted group, whereas participants in the nonaddicted group appeared to show little preoccupation with their smartphone. The attachment and proximity-seeking theme appeared to demarcate between the addicted and nonaddicted groups. An overattachment to a behavior or object is considered to be the defining feature of addictive behavior (Orford, 2001). This study subsumed the theme of "sense of self" within salience because many of the addicted participants felt the smartphone was an extension of their self and their smartphones reflected their sense of self-identity (Srivastava, 2005), because of whom they are and how they want to present themselves to others. Cognitive and behavioral salience has also been reported in the other qualitative studies of smartphone users (Walsh et al., 2008).

Evidence of mood modification was found among both addicted and non-addicted smartphone users. For both participant groups, smartphones provided solace from stress and from boredom and elevated their negative state to a more positive one. In modern society, individuals live 
technology-mediated lives and therefore many users rationalize that smartphone addiction would not be as harmful as addictions to smoking or drug use (Walsh et al., 2008). There is some evidence that mobile phone use increases social inclusion and connectedness especially with friends and peers (Wei \& Lo, 2006) and life satisfaction among younger adults (Wong \& Ma, 2016). In most contemporary families, the use of smartphones and the digital media is the new cultural norm and therefore children from a very early stage have learned to use them (Kuss \& Griffiths, 2017).

From elementary schools to college, social media is empowering students, teachers, and parents to share information and to build community. However, many individuals have sacrificed conversation over connection in the current technological society and have replaced reflective face-to-face communications with online snippets or sips of conversation (Turkle, 2012). Because of these changes in the way individuals currently live their lives, smartphones have become an important source of mood modification for all types of smartphone user. However, there was some difference in pattern noticed between the groups examined in this study because non-addicted smartphone users reported being burdened by the excessive use of smartphones. This resulted in negative reinforcement for nonaddicts, while addicted users often rationalized and failed to realize such negative effects. Gaffney, Thorpe, Young, Collett, and Occhipinti (1998) stated that whether a behavior is addictive or not partly depends on the realization of the benefits of that behavior.

Tolerance was found to be contextualized in both groups of smartphone users. However, non-addicted smartphone users were found to be conscious of their occasional excessive use and thus had more control over their usage. The increasing use of smartphones over time as an indicator of tolerance is highly tentative (Billieux et al., 2015); there are many social and contextual factors that would lead to increase of smartphone use over time. First, smartphones have replaced many other traditional devices such as an alarm clock, camera, music system, DVD, diaries, phone book, reminders, and books (Walsh et al., 2008) and new apps are added every day. Billieux et al. (2015) identified variables that can influence smartphone use including social and contextual factors such as age, relationship status, types of subscription, holidays versus working, occupation, and significant life events. These could also impact on whether individuals develop a tolerance to smartphone use. For participants in this study, living in the college residences away from the family and the absence of strict time schedules in their new residences are other contextual factors reported by the participants of the present research study. The contextual nature of tolerance was evident in this study. However, non-addicted participants had more control over their usage and they were also fully aware of their increasing usage, unlike those in the addicted group.

Withdrawal symptoms of distress and uneasiness were clearly present among five of the addicted group, whereas only two participants in the non-addicted group reported such feelings when they were unable to use their smartphone. Typical symptoms included irritability, distress, and/ or strange feelings when participants were unable to use their smartphones. This is in accordance with previous studies (e.g., Billieux et al., 2015). The presence of FOMO in both groups reflected the contemporary cultural norms of the "always on" culture (Kuss \& Griffiths, 2017). Despite the presence of FOMO in the non-addicted participants, there was no significant distress among this group compared to the addicted group.

Conflict was found among 10 participants across both the groups. However, the descriptions differed and conflict was more noticeable in the addicted group. Young people's connectedness to others as a reason for excessive mobile phone use has been reported by others (e.g., Walsh et al., 2008). Even among non-problematic users, smartphones can serve as a significant distraction from work and/or education. Even non-addicted users in this study perceived that there had been an intrusion into their personal life created by their smartphones. However, none of the addicted smartphone participants tried to justify the conflict, whereas two of the non-addicted participants felt they had to justify their smartphone use to parents. Almost all the participants had tried to cut their smartphone use at some time by adopting many strategies. However, non-addicts had better control over cutting down their smartphone usage than the addicts. However, relapse was not explicitly reported by any of the participants.

\section{Limitations}

This study used a non-validated set of screening questions to operationalize participants as addicted or non-addicted. This limits the interpretation of the findings as none of the participants were provided a diagnosis by a clinical practitioner. Furthermore, there was no assessment regarding smartphone severity or motivation for using smartphones to additionally demarcate the two groups of participants. In addition, there was no rigorous profiling of participants such as their social/emotional state or their professional/academic identities, etc. There are reports that smartphone addiction may be comorbid with other mental health issues. Although the study provided good support to the component model of behavioral addiction, the results must be interpreted with caution because the sample of the study comprised self-report data that are subject to well-known biases. It should also be noted that all the participants operationalized as smartphone addicts were female; therefore, gender differences could not be explored.

\section{CONCLUSIONS}

The main findings of this study provided good support for the components of behavioral addiction outlined by Griffiths (2005). However, the differences between the two groups of smartphone users were sometimes subtle, with "addicted" users showing more signs of emotional dependence on the device and less ability to control their use. Both groups had overlapping thoughts and sentiments concerning their smartphones. More specifically, there was some evidence of demarcation between two groups of smartphone users on the dimensions of salience, tolerance, withdrawal, and 
conflict. Mood modification was not much different in either group, and relapse was not reported by any one of the participants from either group. Some social and contextual factors were also found with regard to tolerance, withdrawal, and relapse. The non-addicted group had much greater control over their smartphone usage than the addicted group on four (of six) aforementioned dimensions of behavioral addiction. The control over smartphone usage was different in the two groups and is one of the important hallmarks of addiction (e.g., Billieux et al., 2008; Khang et al., 2013; Walsh et al., 2008). However, it was also evident from the interviews with participants in this study that the smartphone is a tool that facilitates young people's connectivity with others. Cassidy (2006) also reported that mobile phones use can be a "positive addiction," although this is highly debatable whether addictions can be positive (Griffiths \& Larkin, 2004). However, this is the first study in which addicted and non-addicted smartphone users have been compared qualitatively (and in-depth) and established that the two groups differed on most core components of behavioral addiction.

Funding sources: No financial support was received for this study from any sources.

Authors' contribution: SJ, MGS, and MDG were all equally involved in the conceptualization and design of the study. Data were collected by SJ. First-level interpretation was carried out by SJ and MGS, which was later refined by MDG. SJ wrote the first draft of the paper, which was further developed by MGS. The paper was finally polished by MDG. All authors read and approved the final version of the manuscript.

Conflict of interest: The authors declare no conflict of interest.

\section{REFERENCES}

Andreassen, C. S., Billieux, J., Griffiths, M. D., Kuss, D. J., Demetrovics, Z., Mazzoni, E., \& Pallesen, S. (2016). The relationship between addictive use of social media and video games and symptoms of psychiatric disorders: A large-scale cross-sectional study. Psychology of Addictive Behaviors, 30(2), 252-262. doi:10.1037/adb0000160

Andreassen, C. S., Griffiths, M. D., Hetland, J., \& Pallesen, S. (2012). Development of a Work Addiction Scale. Scandinavian Journal of Psychology, 53(3), 265-272. doi:10.1111/ j.1467-9450.2012.00947.x

Andreassen, C. S., Pallesen, S., Griffiths, M. D., Torsheim, T., \& Sinha, R. (2018). The development and validation of the Bergen-Yale Sex Addiction Scale with a large national sample. Frontiers in Psychology, 9, 144. doi:10.3389/fpsyg.2018. 00144

Belk, R. (1988). Possession and the extended self. Journal of Consumer Research, 15(2), 139-168. doi:10.1086/209154

Belk, R. (2013). Extended self in a digital world. Journal of Consumer Research, 40(3), 477-500. doi:10.1086/671052
Beranuy, M., Oberst, U., Carbonell, X., \& Chamarro, A. (2009). Problematic Internet and mobile phone use and clinical symptoms in college students: The role of emotional intelligence. Computers in Human Behavior, 25(5), 1182-1187. doi:10.1016/j.chb.2009.03.001

Bhutia, Y., \& Tariang, A. (2016). Mobile phone addiction among college going students in Shillong. International Journal of Education and Psychological Research, 5(2), 29-35.

Bian, M., \& Leung, L. (2014). Linking loneliness, shyness, smartphone addiction symptoms, and patterns of smartphone use to social capital. Social Science Computer Review, 33(1), 61-79. doi:10.1177/0894439314528779

Bianchi, A., \& Phillips, J. G. (2005). Psychological predictors of problem mobile phone use. CyberPsychology \& Behavior, 8(1), 39-51. doi:10.1089/cpb.2005.8.39

Billieux, J., Maurage, P., Lopez-Fernandez, O., Kuss, D. J., \& Griffiths, M. D. (2015). Can disordered mobile phone use be considered a behavioral addiction? An update on current evidence and a comprehensive model for future research. Current Addiction Reports, 2(2), 156-162. doi:10.1007/ s40429-015-0054-y

Billieux, J., Van der Linden, M., \& Rochat, L. (2008). The role of impulsivity in actual and problematic use of the mobile phone. Applied Cognitive Psychology, 22(9), 1195-1210. doi:10.1002/acp.1429

Bodford, J. E., Kwan, V. S., \& Sobota, D. S. (2017). Fatal attractions: Attachment to smartphones predicts anthropomorphic beliefs and dangerous behaviors. Cyberpsychology, Behavior, and Social Networking, 20(5), 320-326. doi:10.1089/ cyber.2016.0500

Carbonell, X., Chamarro, A., Griffiths, M., Oberst, U., Cladellas, R., \& Talarn, A. (2012). Problematic Internet and cell phone use in Spanish teenagers and young students. Anales de Psicología, 28(3), 789-796. doi:10.6018/analesps.28.3. 156061

Cassidy, S. (2006). Using social identity to explore the link between a decline in adolescent smoking and an increase in mobile phone use. Health Education, 106(3), 238-250. doi:10.1108/09654280610658578

Chen, Y. F. (2006). Social phenomena of mobile phone use: An exploratory study in Taiwanese college students. Journal of Cyber Culture and Information Society, 11, 219-244.

Chóliz, M. (2012). Mobile-phone addiction in adolescence: The Test of Mobile Phone Dependence (TMD). Progress in Health Sciences, 2(1), 33-44.

Clayton, R. B., Leshner, G. B., \& Almond, A. B. (2015). The extended iSelf: The impact of iPhone separation on cognition, emotion, and physiology. Journal of Computer-Mediated Communication, 20(2), 119-135. doi:10.1111/jcc4.12109

De-Sola Gutiérrez, J., Rodríguez de Fonseca, F., \& Rubio, G. (2016). Cell-phone addiction: A review. Frontiers in Psychiatry, 7(175), 1-15. doi:10.3389/fpsyt.2016.00175

Downe-Wambolt, B. (1992). Content analysis: Method, applications and issues. Health Care for Women International, 13(3), 313-321. doi:10.1080/07399339209516006

Ehrenberg, A., Juckes, S., White, K. M., \& Walsh, S. P. (2008). Personality and self-esteem as predictors of young people's technology use. CyberPsychology \& Behavior, 11(6), 739-741. doi:10.1089/cpb.2008.0030

Gaffney, L. R., Thorpe, K., Young, R., Collett, R., \& Occhipinti, S. (1998). Social skills, expectancies, and drinking in adolescents. 
Addictive Behaviors, 23(5), 587-599. doi:10.1016/S03064603(98)00025-2

García-Oliva, C., \& Piqueras, J. A. (2016). Experiential avoidance and technological addictions in adolescents. Journal of Behavioral Addictions, 5(2), 293-303. doi:10.1556/2006.5. 2016.041

Griffiths, M. D. (2005). A 'components' model of addiction within a biopsychosocial framework. Journal of Substance Use, 10(4), 191-197. doi:10.1080/14659890500114359

Griffiths, M. D. (2010). The role of context in online gaming excess and addiction: Some case study evidence. International Journal of Mental Health and Addiction, 8(1), 119-125. doi:10.1007/s11469-009-9229-x

Griffiths, M. D. (2013). Adolescent mobile phone addiction: A cause for concern? Education and Health, 31(3), 76-78.

Griffiths, M. D. (2015). Problematic technology use during adolescence: Why don't teenagers seek treatment? Education and Health, 33(1), 6-9.

Griffiths, M. D., \& Larkin, M. (2004). Conceptualizing addiction: The case for a 'complex systems' account. Addiction Research and Theory, 12(2), 99-102. doi:10.1080/1606635042000 193211

Griffiths, M. D., Szabo, A., \& Terry, A. (2005). The Exercise Addiction Inventory: A quick and easy screening tool for health practioners. British Journal of Sports Medicine, 39, e30. doi:10.1136/bjsm.2004.017020

Han, S., Kim, K. J., \& Kim, J. H. (2017). Understanding nomophobia: Structural equation modeling and semantic network analysis of smartphone separation anxiety. Cyberpsychology, Behavior, and Social Networking, 20(7), 419-427. doi:10.1089/cyber.2017.0113

Harkin, J. (2003). Mobilisation: The growing public interest in mobile technology. London, UK: Demos.

Hickey, G., \& Kipping, C. (1996). Issues in research. A multi-stage approach to the coding of data from open-ended questions. Nurse Researcher, 4(1), 81-91. doi:10.7748/nr.4.1.81.s9

Hooper, V., \& Zhou, Y. (2007). Addictive, dependent, compulsive? A study of mobile phone usage. Bled 2007 Proceedings, 38. Retrieved September 5, 2019, from http://aisel.aisnet.org/ bled2007/38

Hsieh, H.-F., \& Shannon, S. E. (2005). Three approaches to qualitative content analysis. Qualitative Health Research, 15(9), 1277-1288. doi:10.1177/1049732305276687

Huffington, A. (2018). An open letter to India on our relationship with technology. The Times of India. Retrieved September 5, 2019, from https://timesofindia.indiatimes.com/

Hussain, Z., Griffiths, M. D., \& Sheffield, D. (2017). An investigation into problematic smartphone use: The role of narcissism, anxiety, and personality factors. Journal of Behavioral Addictions, 6(3), 378-386. doi:10.1556/2006.6.2017.052

Igarashi, T., Motoyoshi, T., Takai, J., \& Yoshida, T. (2008). No mobile, no life: Self-perception and text-message dependency among Japanese high school students. Computers in Human Behavior, 24(5), 2311-2324. doi:10.1016/j.chb.2007.12.001

James, D., \& Drennan, J. (2005, January). Exploring addictive consumption of mobile phone technology. Paper presented at the Australian and New Zealand Marketing Academy Conference, Perth, Australia.

Kardefelt-Winther, D., Heeren, A., Schimmenti, A., , Heeren, A., Rooij, A. V., Maurage, P., Michelle, C., Edman, J., Blaszcynski, A., Khazaal, Y., \& Billieux, J. (2017). How can we conceptualize behavioural addiction without pathologizing common behaviors? Addiction, 112(10), 1709-1715. doi:10.1111/add.13763

Katz, J. E., \& Sugiyama, S. (2005). Mobile phones as fashion statements: The co-creation of mobile communication's public meaning. In R. Ling \& P. Pederson (Eds.), Mobile сотmunications: Re-negotiation of the social sphere (pp. 63-81). Surrey, UK: Springer.

Khang, H., Kim, J. K., \& Kim, Y. (2013). Self-traits and motivations as antecedents of digital media flow and addiction: The Internet, mobile phones, and video games. Computers in Human Behavior, 29(6), 2416-2424. doi:10.1016/j.chb. 2013.05.027

Király, O., Nagygyörgy, K., Griffiths, M. D., \& Demetrovics, Z. (2014). Problematic online gaming. In K. Rosenberg \& L. Feder (Eds.), Behavioral addictions: Criteria, evidence and treatment (pp. 61-95). New York, NY: Elsevier.

Ko, K. (2015). A phenomenological case study on the psychological and spiritual conflict resulting from excessive use of smartphones - Focused on Christian university students. Indian Journal of Science and Technology, 8(S1), 398-404. doi:10.17485/ijst/2015/v8iS1/59352

Koo, H. Y. (2010). Cell phone addiction in highschool students and its predictors. Journal of Korean Academy of Child Health Nursing, 16(3), 203-210. doi:10.4094/jkachn.2010.16.3.203

Kuss, D., \& Griffiths, M. (2017). Social networking sites and addiction: Ten lessons learned. International Journal of Environmental Research and Public Health, 14(3), 311. doi:10.3390/ijerph14030311

Kuss, D. J., Shorter, G. W., Van Rooij, A. J., Griffiths, M. D., \& Schoenmakers, T. M. (2013). Assessing Internet addiction using the parsimonious Internet addiction components model A preliminary study. International Journal of Mental Health and Addiction, 12, 351-366. doi:10.1007/s11469013-9459-9

Lapointe, L., Boudreau-Pinsonneault, C., \& Vaghefi, I. (2013). Is smartphone usage truly smart? A qualitative investigation of IT addictive behaviors. Paper presented at 2013 46th Hawaii International Conference on System Sciences, IEEE, Wailea, HI.

Lemmens, J. S., Valkenburg, P. M., \& Peter, J. (2009). Development and validation of a Game Addiction Scale for adolescents. Media Psychology, 12(1), 77-95. doi:10.1080/15213260802669458

Leung, L. (2007). Leisure, boredom, sensation seeking, selfesteem, addiction symptoms and patterns of cell phone use. In E. A. Konijn, M. A. Tanis, S. Utz, \& A. Linden (Eds.), Mediated interpersonal communication (pp. 359-381). Mahwah, NJ: Lawrence Erlbaum Associates.

Leung, L. (2008). Linking psychological attributes to addiction and improper use of the mobile phone among adolescents in Hong Kong. Journal of Children and Media, 2(2), 93-113. doi:10.1080/17482790802078565

Lopez-Fernandez, O., Kuss, D. J., Romo, L., Morvan, Y., Kern, L., Graziani, P., Rousseau, A., Rumpf, H. J., Bischof, A., Gässler, A. K., Schimmenti, A., Passanisi, A., Männikkö, N., Kääriänen, M., Demetrovics, Z., Király, O., Chóliz, M., Zacarés, J. J., Serra, E., Griffiths, M. D., Pontes, H. M., Lelonek-Kuleta, B., Chwaszcz, J., Zullino, D., Rochat, L., Achab, S., \& Billieux, J. (2017). Self-reported dependence on mobile phones in young adults: A European cross-cultural empirical survey. Journal of Behavioral Addictions, 6(2), 168-177. doi:10.1556/2006.6. 2017.020 
Martinotti, G., Villella, C., Di Thiene, D., Di Nicola, M., Bria, P., Conte, G., Cassano, M., Petruccelli, F., Corvasce, N., Janiri, L., \& La Torre, G. (2011). Problematic mobile phone use in adolescence: A cross-sectional study. Journal of Public Health, 19(6), 545-551. doi:10.1007/s10389-011-0422-6

Merlo, L. J., Stone, A. M., \& Bibbey, A. (2013). Measuring problematic mobile phone use: Development and preliminary psychometric properties of the PUMP Scale. Journal of Addiction, 2013, 1-7. doi:10.1155/2013/912807

Mobile Marketing Association. (2016). Kantar IMRB \& MMA launch a comprehensive report on smartphone and feature phone trends. Business Wire India [Delhi NCR India]. Retrieved September 5, 2019, from https://businesswireindia. com/news/news-details/kantar-imrb-mma-launch-comprehensivereport-smartphone-feature-phone-trends/51492

Orford, J. (2001). Excessive appetites: A psychological view of the addictions (2nd ed.). Chichester, UK: Wiley.

Panova, T., \& Carbonell, X. (2018). Is smartphone addiction really an addiction? Journal of Behavioral Addictions, 7(2), 252-259. doi:10.1556/2006.7.2018.49

Perry, S. D., \& Lee, K. C. (2007). Mobile phone text messaging overuse among developing world university students. Communication, 33(2), 63-79. doi:10.1080/02500160701685417

Potter, W. J., \& Levine-Donnerstein, D. (1999). Rethinking validity and reliability in content analysis. Journal of Applied Communication Research, 27(3), 258-284. doi:10.1080/ 00909889909365539

Salehan, M., \& Negahban, A. (2013). Social networking on smartphones: When mobile phones become addictive. Computers in Human Behavior, 29(6), 2632-2639. doi:10.1016/ j.chb.2013.07.003

Smith, A., Rainie, L., McGeeney, K., Keeter, S., \& Duggan, M. (2015). US smartphone use in 2015. Retrieved September 9, 2019, from http://www.pewinternet.org/2015/ 04/01/us-smartphone-use-in-2015/

Soror, A. A., Hammer, B. I., Steelman, Z. R., Davis, F. D., \& Limayem, M. M. (2015). Good habits gone bad: Explaining negative consequences associated with the use of mobile phones from a dual-systems perspective. Information Systems Journal, 25(4), 403-427. doi:10.1111/isj.12065
Srivastava, L. (2005). Mobile phones and the evolution of social behaviour. Behaviour and Information Technology, 24(2), 111-129. doi:10.1080/01449290512331321910

Takao, M., Takahashi, S., \& Kitamura, M. (2009). Addictive personality and problematic mobile phone use. CyberPsychology \& Behavior, 12(5), 501-507. doi:10.1089/cpb.2009.0022

Toda, M., Monden, K., Kubo, K., \& Morimoto, K. (2006). Mobile phone dependence and health-related lifestyle of university students. Social Behavior and Personality, 34(10), 1277-1284. doi:10.2224/sbp.2006.34.10.1277

Tossell, C., Kortum, P., Shepard, C., Rahmati, A., \& Zhong, L. (2015). Exploring smartphone addiction: Insights from longterm telemetric behavioral measures. International Journal of Interactive Mobile Technologies, 9(2), 37-43. doi:10.3991/ ijim.v9i2.4300

Tripathi, P. (2018). Smartphone users in India 2018: 16\% YoY growth is the highest in the world. Retrieved September 9, 2019, from https://dazeinfo.com/2018/05/07/smartphoneusers-in-india-2018-2022-growth/

Turkle, S. (2012). The flight from conversation. New York Times (Sunday Review). Retrieved September 9, 2019, from http:// www.nytimes.com/2012/04/22/opinion/sunday/the-flight-fromconversation.html?pagewanted=all\&_r=0

Walsh, S. P., White, K. M., \& Young, R. M. (2008). Over-connected? A qualitative exploration of the relationship between Australian youth and their mobile phones. Journal of Adolescence, 31(1), 77-92. doi:10.1016/j.adolescence.2007. 04.004

Walsh, S. P., White, K. M., \& Young, R. M. (2010). Needing to connect: The effect of self and others on young people's involvement with their mobile phones. Australian Journal of Psychology, 62(4), 194-203. doi:10.1080/00049530903567229

Wei, R., \& Lo, V.-H. (2006). Staying connected while on the move: Cell phone use and social connectedness. New Media \& Society, 8(1), 53-72. doi:10.1177/1461444806059870

Wong, T. K., \& Ma, W. W. K. (2016, June 9-13). Exploring relationship between online social support and individual online subjective well-being among young adults. Paper presented at 66th ICA Annual Conference (International Communication Association), Fukuoka, Japan. 